\title{
Effect of Shallow-Buried High-Intensity Mining on Soil Water Content in Ningtiaota Minefield
}

\author{
Fan Cui ${ }^{1,2,3, *}$, Yunfei Du ${ }^{1} \mathbb{D}$, Jianyu Ni ${ }^{1}$, Zhirong Zhao ${ }^{1}$ and Shiqi Peng ${ }^{1}$ \\ 1 School of Geosciences and Surveying Engineering, China University of Mining and Technology (Beijing), \\ Beijing 100083, China; yunfei_du@126.com (Y.D.); nijianyu11@126.com (J.N.); \\ zhirong_zhao1120@163.com (Z.Z.); pengshiqi1119@126.com (S.P.) \\ 2 State Key Laboratory of Coal Resources and Safe Mining, China University of Mining and \\ Technology (Beijing), Beijing 100083, China \\ 3 Beijing Key Laboratory for Precise Mining of Intergrown Energy and Resources, China University of Mining \\ and Technology (Beijing), Beijing 100083, China \\ * Correspondence: cuifan@cumtb.edu.cn; Tel.: +86-139-1157-0965
}

\section{check for}

updates

Citation: Cui, F.; Du, Y.; Ni, J.; Zhao, Z.; Peng, S. Effect of Shallow-Buried High-Intensity Mining on Soil Water Content in Ningtiaota Minefield.

Water 2021, 13, 361. https://doi.org/ $10.3390 /$ w13030361

Academic Editor: Domenico Cicchella Received: 24 December 2020

Accepted: 26 January 2021

Published: 30 January 2021

Publisher's Note: MDPI stays neutral with regard to jurisdictional claims in published maps and institutional affiliations.

Copyright: (c) 2021 by the authors. Licensee MDPI, Basel, Switzerland. This article is an open access article distributed under the terms and conditions of the Creative Commons Attribution (CC BY) license (https:/ / creativecommons.org/licenses/by/ $4.0 /)$.

\begin{abstract}
Shallow-buried high-intensity mining (SHM) activities commonly in China's western mining area will lead to the decrease of groundwater level and soil water content (SWC), which will aggravate the further deterioration of the local fragile ecological environment. In this study, the applicability and limitations of six typical soil dielectric models were comprehensively evaluated based on ground penetrating radar (GPR) technology and shallow drilling methods. Moreover, experiments were performed to test the variation of SWC in Ningtiaota minefield affected by the SHM. The results show that the fitting effect of the four empirical models and two semi-empirical models on the clay is better than that of the medium sand. Among the six models, the Ledieu model has the best performance for medium sand, and the Topp model for clay. After SHM, the shallow SWC decreases as a whole. The decreasing range is $4.37-15.84 \%$, showing a gradual downward trend compared with the one before mining. The shorter the lagging working face distance, the greater the drop of SWC will be. The longer the lagging working face distance, the smaller the drop of SWC will be showing a gradual and stable trend.
\end{abstract}

Keywords: arid and semi-arid areas; shallow-buried high-intensity mining; soil water content; bulk dielectric permittivity

\section{Introduction}

Mineral resources provide a powerful impetus for the development of human society. However, due to its long formation cycle, low reserves, early extensive mining, the problems of regional land use change, and ecological environment deterioration have become increasingly serious [1,2]. The impact from mineral resources exploitation on the ecological environment has become a hot research topic for scholars [3-10]. Coal, as China's most important fossil energy source, accounts for more than $60 \%$ of China's energy structure [11], which plays a very important role in promoting the development of the national economy and social progress. With the gradual depletion of coal resources in eastern China, the focus of coal development has shifted to the northwest arid and semi-arid areas with fragile ecological and geological environment $[12,13]$. Shanxi Province, Shaanxi Province, and the western part of Inner Mongolia Autonomous Region have gradually become the main coal producing areas in western China [14]. These areas have many mineable coal seams, shallow burials, large thicknesses, abundant coal resources, and uncomplicated geological conditions. [15] With the improvement of coal mining technology and equipment, highintensity mining is becoming more common in these areas to meet the increasing coal demand $[16,17]$. Compared to the situation of great burial depth and low mining intensity, the rock formation and surface damage caused by SHM show new characteristics, such 
as the serious "two zone" characteristics of serious damage to the overlying stratum, the strong work surface pressure, and the severe damage to the surface [18]. The decline of groundwater level and the decrease of SWC caused by high-intensity mining in shallow buried coal seams aggravate the water resources shortage and the fragile ecological environment in the mining areas [19]. In order to realize the coordinated development of high-efficiency green mining of coal resources and ecological environment protection, it is necessary and urgent to study the impact of SHM on the shallow SWC.

As the most important ecological environmental factor in arid and semi-arid areas, water determines the ecological environment evolution process of oasis and desertification in the areas [20]. As the content of soil organic matter and soil inorganic nutriments in shallow stratum is low, which is the case in arid and semi-arid coal mining areas, the main factors affecting the quality of land reclamation are soil media and SWC $[21,22]$. Therefore, the distribution of SWC is a key factor affecting vegetation growth and ecological environment in this area [23]. It is of vital significance to measure the SWC of shallow strata quickly and accurately for environmental governance and ecological restoration [24,25]. Currently, the common methods for measuring SWC include gravimetric method [26], time domain reflection method (TDR) [27], frequency domain reflection method (FDR) [28], radiation method [29], ground penetrating radar method (GPR) [30], and remote sensing method [31]. The gravimetric method is easy to operate and accurate and can be used as a standard for testing other soil water detection methods. However, this method is time-consuming and laborious, and will damage the soil structure, which will result in the inability to measure the soil samples multiple times to obtain continuous soil moisture conditions at the same location [32]. TDR, FDR, and radiation methods are all implemented in single-point measurement methods, which cannot meet the needs for measuring the large range of soil in coal mining areas quickly and continuously [33]. Remote sensing methods have the characteristics of high timeliness and strong dynamic contrast and can monitor large ranges of SWC and other information for a long time. However, it can only measure the superficial layers of the soil [34,35].

The GPR method has been widely popular with many scholars because it can realize continuous, rapid and large-scale SWC detection [36-40]. The GPR method has great advantages in the detection of SWC in large-area mining areas. The method is usually based on the construction of quantitative relationships between media SWC and dielectric permittivity $[41,42]$. Scholars have conducted a lot of research on the relationship between dielectric permittivity and SWC in different soil conditions, and proposed many interesting dielectric-water content models, such as, the empirical models put forward by Topp et al. [43] (1980), Ledieu et al. [44] (1986), Alharthi et al. [45] (1987), Roth et al. [46] (1992), and Pepin et al. [47] (2011), the semi-empirical models put forward by Roth et al. [48] (1990) and Malicki et al. [49] (1996), and the theoretical models put forward by Cosenza et al. [50] (2003) and Chelidze and Guéguen [51] (1999). However, there are still some limitations in adaptability. For example, the Alharthi model is obtained at room temperature, and the Pepin model is used for organic soils. The theoretical model can generally reflect the main characteristics of the soil geometric structure, but the results are not ideal for soils with complex structures and strong interactions between phases.

Therefore, in this study the aim is to calculate the corresponding water content values according to six typical water content models and compare them with the water content value measured by the gravimetric method to comprehensively evaluate the applicability and limitations of the models. The dielectric permittivity is calculated using precise wave speed of radar waves obtained by GPR data and drilling methods. Moreover, it compares the changes in water content before and after mining to analyze the effect of SHM on the shallow SWC in the minefield. The research can provide a theoretical basis for ecological restoration work such as vegetation restoration and farmland reclamation in the ecologically fragile areas of the SHM area. 


\section{Materials and Methods}

\subsection{Study Area}

Ningtiaota minefield is located in the northwest of Shenmu county, Yulin city, Shaanxi province, China, within an area of $136.1 \mathrm{~km}^{2}$. The location is shown in Figure 1. The stratum in the minefield is mild, and the surface is aeolian sand landform. The soil type and granularity distribution in the study area measured by the experiment are shown in Table 1 . The area is arid, dry and has a large amount of evaporation. The average annual precipitation is $427.8 \mathrm{~mm}$, and the average potential evapotranspiration is $1788.4 \mathrm{~mm}$. Rainfall is mostly concentrated within the period from July to September and is characterized by semi-arid continental monsoon climates. The minefield has a multi-year average temperature of $8.6^{\circ} \mathrm{C}$, a maximum average temperature of $23.9^{\circ} \mathrm{C}$ in July, and a minimum average temperature of $-9.3^{\circ} \mathrm{C}$ in January. Vegetation is dominated by sandy vegetation such as Salix Psammophila, Artemisia Desterorum, and Caragana Korshinskii. There are mainly two rivers in the minefield, Kaokaowusu Ditch and Zhugai Ditch. Kaokaowusu Ditch is the northern boundary of the south wing of the coal mine, traversing the central and northern part of the minefield from west to east. With a total length of $41.9 \mathrm{~km}$ and a drainage area of $259.5 \mathrm{~km}^{2}$, the river has been observed for many years with a general flow rate of $0.410-1.768 \mathrm{~m}^{3} / \mathrm{s}$. Zhugai Ditch is located at the northern boundary of the minefield, with a river length of $29 \mathrm{~km}$ and a drainage area of $177 \mathrm{~km}^{2}$. The river flow is strongly affected by seasonal rainfall.

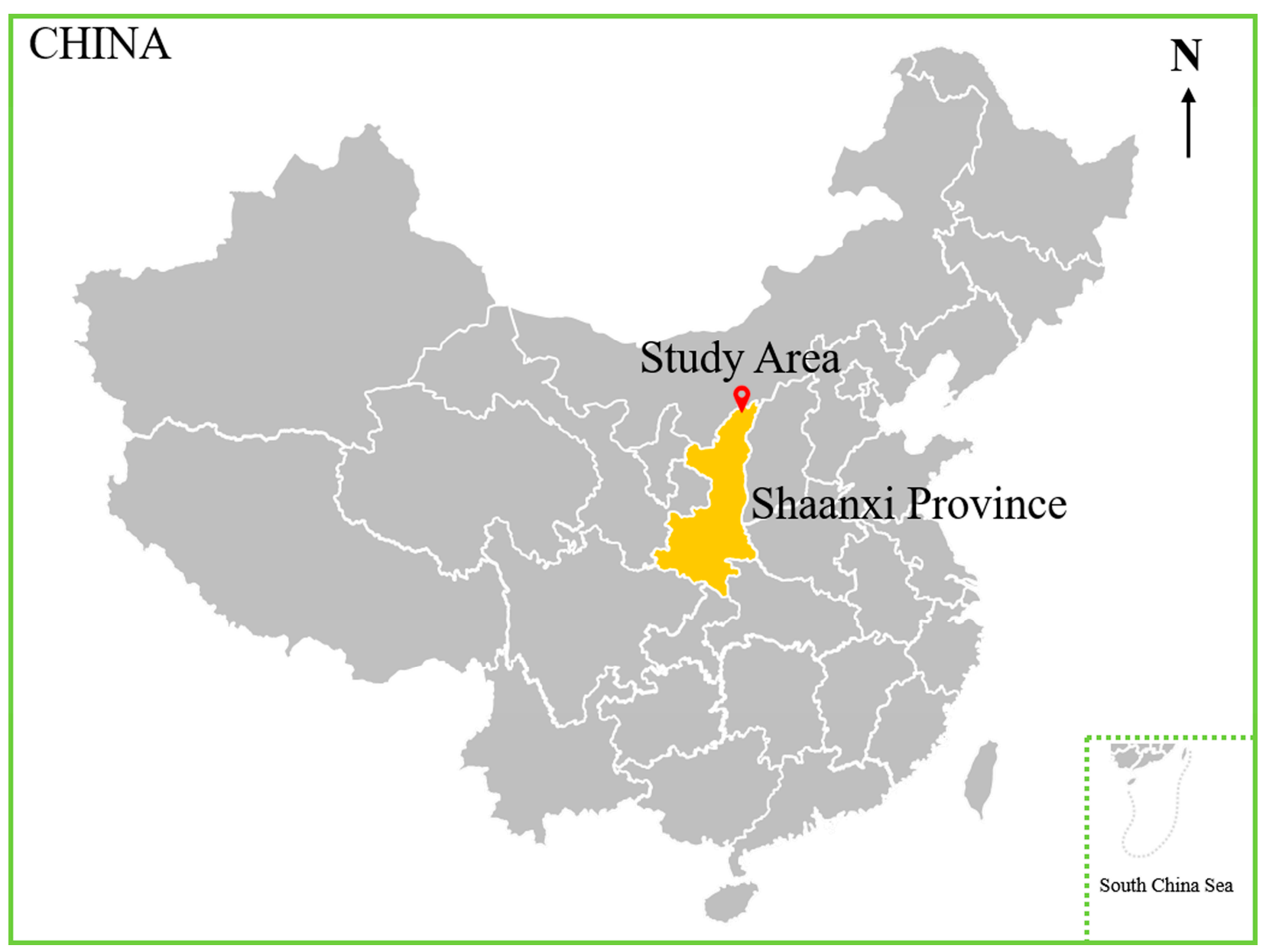

Figure 1. Geographical location map of Ningtiaota minefield. 
Table 1. Soil type and granularity distribution in the study area.

\begin{tabular}{cccc}
\hline Soil Types & $\begin{array}{c}\text { Percentage of Clay (\%), } \\
<\mathbf{0 . 0 0 5} \mathbf{~ m m}\end{array}$ & $\begin{array}{c}\text { Percentage of Silt (\%), } \\
\mathbf{0 . 0 0 5 - 0 . 2 5} \mathbf{~ m m}\end{array}$ & $\begin{array}{c}\text { Percentage of Sand (\%), } \\
\mathbf{0 . 2 5}-\mathbf{0 . 5} \mathbf{~ m m}\end{array}$ \\
\hline Medium sand & 12 & 27 & 61 \\
clay & 40 & 42 & 18 \\
\hline
\end{tabular}

Ningtiaota minefield adopts inclined shaft development and fully mechanized caving technologies. The working faces (S12001, S12002, and S12003) in the south wing of the Ningtiaota minefield are used as detection and sampling areas. The location of the study area is shown in Figure 2a. The distance from the southern boundary of the study area to the open-off cut of the working face is $1075 \mathrm{~m}$. S12001, S12002, and S12003 work surface are typically buried at shallow depths, with high-yield, large work surface, and fast promotion of a thick mining working face. The working faces (S12001, S12002, and S12003) are typical high-strength mining working faces with shallow depth, large mining height, large working face, rapid advance, and full-thickness mining at one time. The coal seam in the study area has a ground elevation above sea level of 1103-1065 m, a burial depth of 14-212 m, a coal seam thickness of 3.70-9.79 m, an average coal seam thickness of $6.60 \mathrm{~m}$, a working face length of 274-344 m, and an average advancing speed of about $10 \mathrm{~m} / \mathrm{d}$.

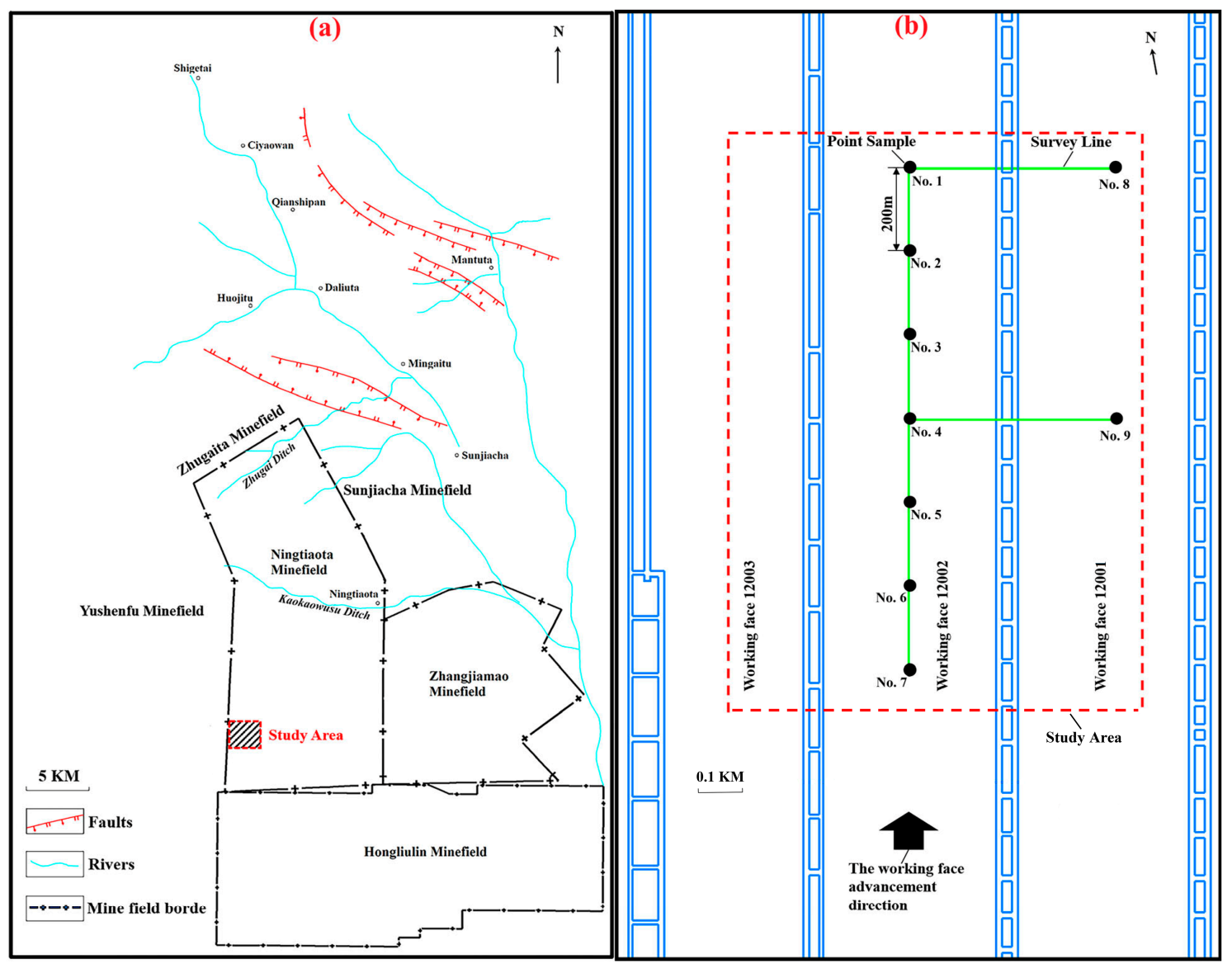

Figure 2. Schematic plan view of the study area. (a) The location of the study area. (b) Layout of survey lines and sampling points in the study area.

\subsection{Survey Lines and Sampling Points Layout}

Three survey lines were laid in the study area. Two of them were arranged along the inclination direction of the working face with a length of $400 \mathrm{~m}$, and the other one was arranged along the strike direction of the working face with a length of $1200 \mathrm{~m}$. The layout 
location is shown in Figure 2b. A sampling point was set every $200 \mathrm{~m}$ for each survey line, and the distribution of sampling points is shown in Figure $2 \mathrm{~b}$. Two sampling operations were designed according to the mining schedule. The first sampling was conducted on 16 December 2019. At this time, the working face had approximately advanced to the vicinity of the southern edge of the study area, and the working face in the study area had not yet been mined. The second sampling was carried out on 1 June 2020, at which point the working face had been pushed away from the study area. Both sampling tasks were completed within 5 days, during which the weather conditions were good. By the time the first sampling began, the working face S12003 had been mined. By the end of the second sampling process, the working face S12001 had not been mined.

\subsection{Sampling Method}

Figure 3 shows the sampling tools and sampling process. During the detection, we set the number of sampling points and the sampling time-window to 1024 and $200 \mathrm{~ns}$, respectively. In shallow strata, the laboratory soil samples were obtained by drilling. For the selected measuring points on each survey line, the Luoyang shovel (Figure 3c) and cutting ring (Figure $3 b$ ) were used as tool to drill and sample. The samples were collected every $0.5 \mathrm{~m}$, the upper limit of the sampling depth was $10 \mathrm{~m}$. When the soil sample in the cutting ring was removed, it was immediately put into an aluminum box and sealed for storage.

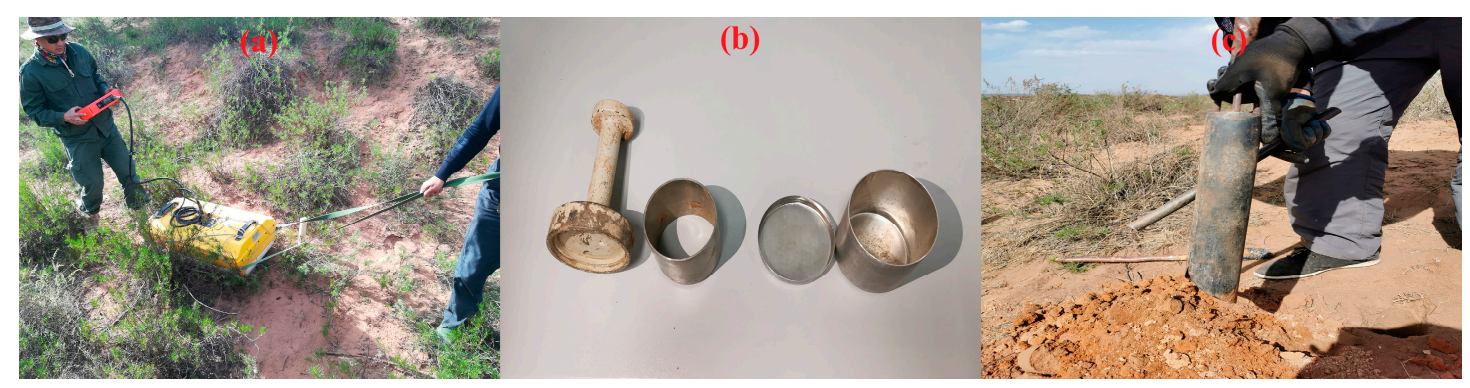

Figure 3. Real shots of the sampling tools and sampling process. (a) The staff are conducting radar detection. (b) The cutting ring and aluminum box used for sampling. (c) Luoyang shovel.

\subsection{GPR Detection Principle (Wave Velocity Calibration Method)}

The GPR emits high-frequency broadband electromagnetic waves in the form of pulses to the underground. When electromagnetic waves propagate underground, the relative permittivity of the medium and the electromagnetic wave velocity satisfy the following relationship [52]:

$$
\left\{\begin{array}{c}
t=\frac{2 z}{v} \\
v=\frac{c}{\sqrt{\varepsilon_{r}}}
\end{array}\right.
$$

where $t$ is the travel time of electromagnetic waves propagating in the medium (ns), $z$ is the depth of the reflecting surface encountered by the electromagnetic wave $(\mathrm{m}), v$ is the propagation speed of electromagnetic waves in the current medium $\left(\mathrm{m} \cdot \mathrm{ns}{ }^{-1}\right), c$ is the propagation speed of electromagnetic waves in vacuum $\left(\mathrm{m} \cdot \mathrm{ns}^{-1}\right)$, and $\varepsilon_{r}$ is the relative permittivity of the current medium.

The two-way travel time of the radar wave reaching the reflective interface in the radar profile is obtained by identifying the reflexion through the GPR data. At the same time, the different soil layers positions in the study area are calibrated based on the drilling sampling results. Obtaining the depth of the medium layer and the travel time of the radar wave, the wave speed of the radar wave in different media can be calculated, then the relative permittivity of different media can be determined. 


\subsection{SWC Calculation Methods}

\subsubsection{Topp Empirical Model (1980)}

Topp et al. [43] established an empirical relationship between soil volumetric water content and soil dielectric permittivity, commonly known as the Topp empirical model, on the basis of the results of tests on four soils in 1980. Compared with other soil dielectricwater content models, the advantage is that only one parameter of the soil dielectric permittivity can determine the SWC, without taking into account other soil parameters such as soil texture, bulk density, temperature, solution salt content, and soil moisture history. These characteristics of the Topp empirical model make it the most widely used general formula, especially for determining the relationship between SWC and soil dielectric permittivity in high frequency domains $(20-1000 \mathrm{MHz})$. The specific expression is shown in Equation (2):

$$
\theta_{V}=-5.3 \times 10^{-2}+2.92 \times 10^{-2} \varepsilon_{r}-5.5 \times 10^{-4} \varepsilon_{r}^{2}+4.3 \times 10^{-6} \varepsilon_{r}^{3}
$$

where $\theta_{V}$ is the calculated volumetric water content $\left(\mathrm{cm}^{3} \cdot \mathrm{cm}^{-3}\right)$ and $\varepsilon_{\mathrm{r}}$ is the relative permittivity of the medium.

\subsubsection{Empirical Models Using the Refractive Index $\sqrt{\varepsilon_{\mathrm{r}}}$}

Ledieu et al. [44] used a time domain reflectometer (TDR) method to measure SWC on site, and used the square root formula to characterize the relationship between volumetric water content and dielectric permittivity:

$$
\theta=5.69 t-17.58
$$

where $\theta$ is the volumetric water content (\%). After removing the percent sign, we can get:

$$
\theta_{V}=0.0569 t-0.1758
$$

It can be seen from Equation (1) that the relative permittivity of the medium and the electromagnetic wave speed satisfy the following relationship:

$$
\sqrt{\varepsilon_{r}}=\frac{c t}{2 z}
$$

where $c$ is the speed of light $\left(3 \times 10^{8} \mathrm{~m} \cdot \mathrm{s}^{-1}\right)$ and $z$ is the probe length $(30 \mathrm{~cm})$. By introducing Equation (5) into Equation (4), we can get the following results:

$$
\theta_{V}=0.1138 \sqrt{\varepsilon_{r}}-0.1758
$$

This type of model formula not only includes the apparent dielectric permittivity measured by TDR, but also considers the bulk density (or porosity). The common Malicki model and its revised model are [49]:

$$
\theta_{V}=\frac{\sqrt{\varepsilon_{r}}-1.44}{7.16}
$$

and

$$
\theta_{V}=\frac{\sqrt{\varepsilon_{r}}-0.819-0.168 \rho_{b}-0.159 \rho_{b}^{2}}{7.17+1.18 \rho_{b}}
$$

where $\rho_{b}$ is the dry soil bulk density $\left(\mathrm{g} \cdot \mathrm{cm}^{-3}\right)$. Equation (7) was obtained by Malicki et al., who selected 62 mineral soil and organic soil samples, and obtained it under the condition of considering only the dielectric permittivity. Equation (8) was obtained by Malicki et al. after considering the bulk density of the soil and re-measured TDR. 


\subsubsection{Roth Electromagnetic Mixing Model (1990)}

Roth et al. [48] considered physical mixing laws and obtained the following relationship by performing analysis of 9 types of mineral soils and 7 types of organic soils in the literature:

$$
\theta_{V}=\frac{\sqrt{\varepsilon_{r}}-0.63-0.62 \rho_{b}}{8.18}
$$

\subsubsection{Roth Empirical Model (1992)}

In 1992, Roth et al. [46] proposed three different empirical formulas for mineral soil, organic soil and magnetic soil. The empirical formula for mineral soil is also similar to the third-order polynomial of the Topp model, but the coefficients are different, and the prediction error is $0.015 \mathrm{~m}^{3} \cdot \mathrm{m}^{-3}$. The specific expression is shown in Equation (10):

$$
\theta_{V}=-7.28 \times 10^{-2}+4.48 \times 10^{-2} \varepsilon_{r}-19.5 \times 10^{-4} \varepsilon_{r}^{2}+36.1 \times 10^{-6} \varepsilon_{r}^{3}
$$

\subsubsection{Gravimetric Method}

The aluminum box containing the soil sample was weighed with a scale to obtain the weight $m_{1}$. Then it was placed in an oven at $105^{\circ} \mathrm{C}$ for about 12 hours until the weight became constant. After that, the mass was weighed and recorded as $m_{2}$. The size of the cutting ring used was $\Phi 50.46 \mathrm{~mm} \times 50 \mathrm{~mm}$, and the volume $V_{0}$ was $100 \mathrm{~cm}^{3}$. The calculation formula for SWC is

$$
\theta_{g}=\frac{m_{1}-m_{2}}{\rho_{w} V 0}
$$

where $\theta_{g}$ represents the water content value obtained by the gravimetric method $\left(\mathrm{cm}^{3} \cdot \mathrm{cm}^{-3}\right)$, $m_{1}$ is the weight of wet soil and aluminum box $(\mathrm{g}), m_{2}$ is the weight of dry soil and aluminum box $(\mathrm{g}), \rho_{w}$ is the density of water $\left(\mathrm{g} \cdot \mathrm{cm}^{-3}\right)$, and $V_{0}$ is the volume of the cutting ring $\left(\mathrm{cm}^{3}\right)$.

\subsection{Error Analysis}

The SWC measured by the gravimetric method was compared with the calculated values of each model based on the GPR data to evaluate the advantages and disadvantages of the six soil dielectric models. The accuracy of the calculated value is reflected by the root mean square error (RMSE). RMSE is the value calculated based on the square root of the mean square error. The closer the RMSE is to 0, the higher the accuracy of fit. RMSE is expressed as

$$
R M S E=\sqrt{\frac{\sum\left(\theta_{g}-\theta_{V}\right)^{2}}{n}}
$$

where $n$ represents the number of experimental observations.

\section{Results and Discussion}

\subsection{Comparative Analysis of SWC Calculation Methods}

The different media positions information and dielectric permittivity obtained from drilling sampling results and GPR data profiles are shown in Table 2. Since clay did not appear in some of the boreholes, 18 sets of medium sand dielectric permittivity, and 16 sets of clay dielectric permittivity were obtained by the GPR wave velocity calibration method.

We compared the calculated SWC with the measured SWC using six typical empirical models, and calculated their root mean square error (RMSE). The results are shown in Figure 4 and Table 3. 
Table 2. The dielectric permittivity of the soil medium at different sampling points obtained by the wave velocity calibration method.

\begin{tabular}{|c|c|c|c|c|c|c|c|c|}
\hline $\begin{array}{l}\text { Sampling } \\
\text { Time }\end{array}$ & $\begin{array}{c}\text { Point } \\
\text { Sample }\end{array}$ & Soil & $\begin{array}{l}\text { Depth } \\
\text { (m) }\end{array}$ & $\begin{array}{c}\text { Thickness } \\
\text { (m) }\end{array}$ & $\begin{array}{l}\text { Time } \\
\text { (ns) }\end{array}$ & $\begin{array}{l}\text { Dielectric } \\
\text { Permittiv- } \\
\quad \text { ity }\end{array}$ & $\begin{array}{c}\text { Measured } \\
\text { water } \\
\text { Content } \\
\left(\mathrm{cm}^{3} \cdot \mathrm{cm}^{-3}\right)\end{array}$ & $\begin{array}{c}\text { Bulk } \\
\text { Density } \\
\left(\mathrm{g} \cdot \mathrm{cm}^{-3}\right)\end{array}$ \\
\hline \multirow{16}{*}{$\begin{array}{l}\text { The first } \\
\text { sampling }\end{array}$} & \multirow{2}{*}{1} & Medium sand & 3.6 & 3.6 & 55 & 5.2517 & 0.0675 & 1.7279 \\
\hline & & clay & 6.3 & 2.7 & 130 & 9.5805 & 0.2017 & 7.6899 \\
\hline & \multirow{2}{*}{2} & Medium sand & 3.9 & 3.9 & 71 & 7.4571 & 0.0716 & 1.6829 \\
\hline & & clay & 6.2 & 2.3 & 136 & 10.8262 & 0.2086 & 1.8927 \\
\hline & \multirow[b]{2}{*}{3} & Medium sand & 1.5 & 1.5 & 27 & 7.2900 & 0.0965 & 1.5674 \\
\hline & & clay & 6.1 & 4.6 & 135 & 11.0202 & 0.2125 & 1.4518 \\
\hline & \multirow[b]{2}{*}{4} & Medium sand & 1.8 & 1.8 & 33 & 7.5625 & 0.0463 & 1.6157 \\
\hline & & clay & 3.8 & 1.5 & 78 & 9.4799 & 0.2229 & 1.6612 \\
\hline & \multirow[b]{2}{*}{5} & Medium sand & 1.5 & 1.5 & 28 & 7.8400 & 0.0749 & 1.3896 \\
\hline & & clay & 5.1 & 2.2 & 114 & 11.2422 & 0.1436 & 1.3266 \\
\hline & \multirow{2}{*}{6} & Medium sand & 2.3 & 2.3 & 42 & 7.5028 & 0.0966 & 1.6781 \\
\hline & & clay & 4.8 & 1.5 & 107 & 11.1807 & 0.2490 & 1.8336 \\
\hline & \multirow{2}{*}{7} & Medium sand & 1.9 & 1.9 & 35 & 7.6350 & 0.1131 & 1.7753 \\
\hline & & clay & 5.8 & 3.9 & 128 & 10.9584 & 0.2295 & 1.6984 \\
\hline & \multirow{2}{*}{8} & Medium sand & 3.4 & 3.4 & 61 & 7.4300 & 0.0568 & 1.6920 \\
\hline & & clay & 7.8 & 2.2 & 158 & 9.2322 & 0.2223 & 1.6587 \\
\hline \multirow{18}{*}{$\begin{array}{l}\text { The second } \\
\text { sampling }\end{array}$} & 9 & Medium sand & 8.7 & 8.7 & 155 & 6.9151 & 0.0529 & 1.5998 \\
\hline & \multirow[b]{2}{*}{1} & Medium sand & 3.4 & 2.9 & 57 & 6.3237 & 0.0553 & 1.5279 \\
\hline & & clay & 5.2 & 1.8 & 116 & 11.1967 & 0.1855 & 1.5886 \\
\hline & \multirow{2}{*}{2} & Medium sand & 2.5 & 2.5 & 38 & 5.1984 & 0.0516 & 1.4775 \\
\hline & & clay & 4.3 & 1.8 & 89 & 9.6389 & 0.1863 & 1.5716 \\
\hline & \multirow{2}{*}{3} & Medium sand & 1.5 & 1.5 & 26 & 6.7600 & 0.0576 & 1.4537 \\
\hline & & clay & 6.5 & 5.0 & 136 & 9.8499 & 0.1952 & 1.4121 \\
\hline & \multirow[b]{2}{*}{4} & Medium sand & 1.5 & 1.5 & 26 & 6.7600 & 0.0418 & 1.5045 \\
\hline & & clay & 2.0 & 0.5 & 41 & 9.4556 & 0.1602 & 1.5988 \\
\hline & \multirow{2}{*}{5} & Medium sand & 2.7 & 2.7 & 44 & 5.9753 & 0.0447 & 1.3831 \\
\hline & & clay & 5.1 & 2.2 & 105 & 9.5372 & 0.1927 & 1.3229 \\
\hline & \multirow[b]{2}{*}{6} & Medium sand & 1.5 & 1.5 & 25 & 6.2500 & 0.0564 & 1.3314 \\
\hline & & clay & 4.7 & 1.2 & 103 & 10.8059 & 0.2067 & 1.5607 \\
\hline & \multirow{2}{*}{7} & Medium sand & 1.8 & 1.8 & 31 & 6.6736 & 0.0866 & 1.6050 \\
\hline & & clay & 4.5 & 2.7 & 102 & 11.5600 & 0.2118 & 1.6213 \\
\hline & 8 & Medium sand & 5.5 & 5.5 & 122 & 8.1804 & 0.1209 & 1.5085 \\
\hline & \multirow{2}{*}{9} & Medium sand & 5.5 & 5.5 & 89 & 5.8258 & 0.0460 & 1.5266 \\
\hline & & clay & 9.3 & 1.5 & 206 & 11.0395 & 0.2105 & 1.3938 \\
\hline
\end{tabular}

It can be seen from Figure 4 and Table 3 that the RMSE value range is 0.0284$0.0549 \mathrm{~cm}^{3} \cdot \mathrm{cm}^{-3}$. The range of RMSE value is $0.0560-0.0968 \mathrm{~cm}^{3} \cdot \mathrm{cm}^{-3}$. On the whole, the degree of fitting of the six empirical models on the clay is better than that of the medium sand. Among the six models, the best model performance for medium sand is the Ledieu model with RMSE of $0.0560 \mathrm{~cm}^{3} \cdot \mathrm{cm}^{-3}$, the followed model is the Topp model with RMSE of $0.0567 \mathrm{~cm}^{3} \cdot \mathrm{cm}^{-3}$, and the worst model is the Maliki 2 model with RMSE of $0.0968 \mathrm{~cm}^{3} \cdot \mathrm{cm}^{-3}$. Although the Ledieu model and the Topp model perform better here, the overall calculation values of these models are too large relative to the measured values, to accurately predict the SWC of the medium sand in the region, and model correction work is needed to obtain better prediction results. For clay, the Topp model has the best performance with RMSE of $0.0284 \mathrm{~cm}^{3} \cdot \mathrm{cm}^{-3}$, and the Malicki 2 model has the worst performance with RMSE of $0.0549 \mathrm{~cm}^{3} \cdot \mathrm{cm}^{-3}$. 

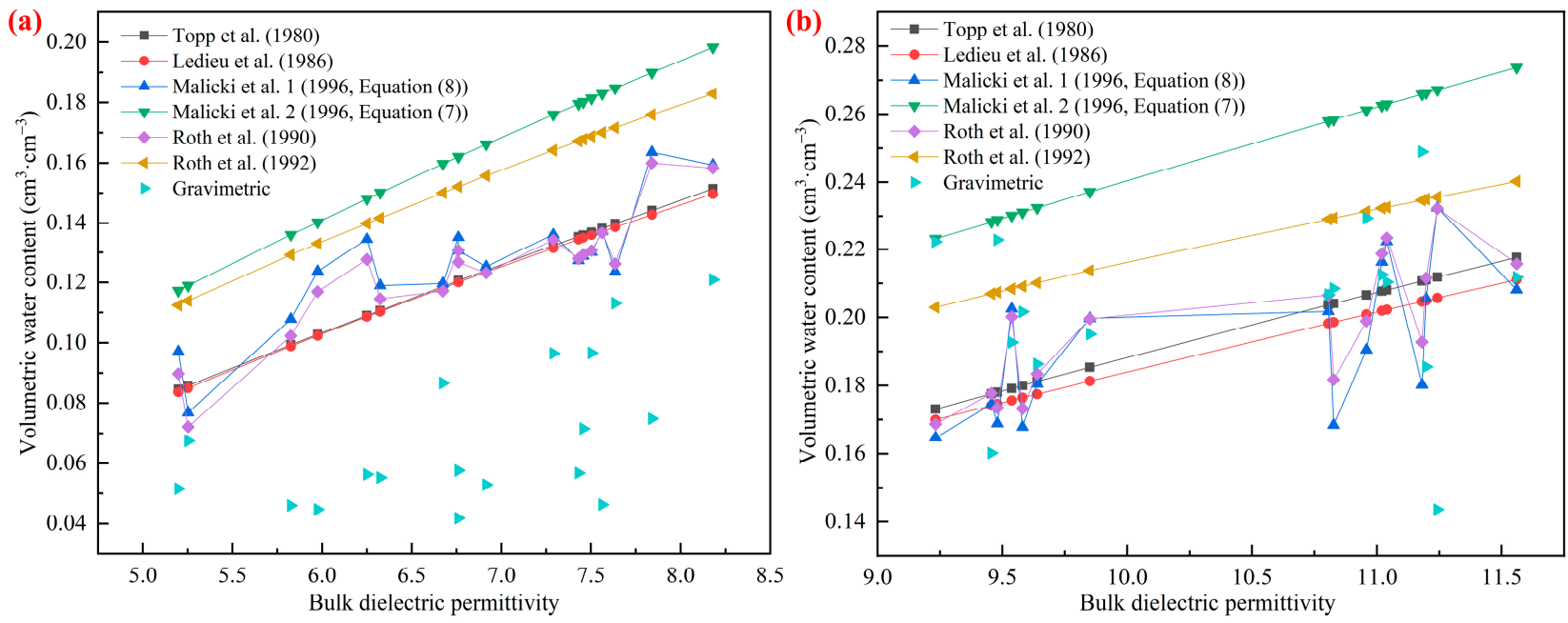

Figure 4. Comparison of calculated soil water content (SWC) and the measured SWC. The calculated SWC value represents the water content value obtained using the typical empirical models. The measured SWC value represents the water content value obtained using the gravimetric method. (a) Comparison of medium sand SWC calculated by dielectric models with that measured by gravimetric method. (b) Comparison of clay SWC calculated by dielectric models with that measured by gravimetric method.

Table 3. Error analysis of calculated SWC by dielectric models and measured SWC by gravimetric method.

\begin{tabular}{|c|c|c|}
\hline Soil Category & Model Name & $\operatorname{RMSE}\left(\mathrm{cm}^{3} \cdot \mathrm{cm}^{-3}\right)$ \\
\hline \multirow{7}{*}{ Medium sand } & Topp et al. [43] & 0.0567 \\
\hline & Ledieu et al. [44] & 0.0560 \\
\hline & Malicki et al. 1 [49] (Equation (8) in this study) & 0.0629 \\
\hline & Malicki et al. 2 [49] (Equation (7) in this study) & 0.0968 \\
\hline & Roth et al. [48] & 0.0600 \\
\hline & Roth et al. [46] & 0.0865 \\
\hline & Topp et al. [43] & 0.0284 \\
\hline \multirow{5}{*}{ Clay } & Ledieu et al. [44] & 0.0294 \\
\hline & Malicki et al. 1 [49] (Equation (8) in this study) & 0.0388 \\
\hline & Malicki et al. 2 [49] (Equation (7) in this study) & 0.0549 \\
\hline & Roth et al. [48] & 0.0355 \\
\hline & Roth et al. [46] & 0.0334 \\
\hline
\end{tabular}

Therefore, it is recommended to use the Topp model to predict clay SWC. The Malicki 1 model and the Roth (1990) model have improved performance in their applicability compared to considering only dielectric permittivity, especially the Malicki 1 model, due to the effect of adding bulk density. However, it should be pointed out that their applicability is still limited to the initial test data or test samples.

\subsection{Variation in Shallow SWC before and after Mining}

We selected point samples 8 and 9 on the working face 12,001 survey line in the unmined area for shallow formation drilling samples to compare the effects of rainfall, evapotranspiration, and other natural conditions on the SWC of shallow formations. The change of SWC obtained by two samplings is shown in Figure 5. 

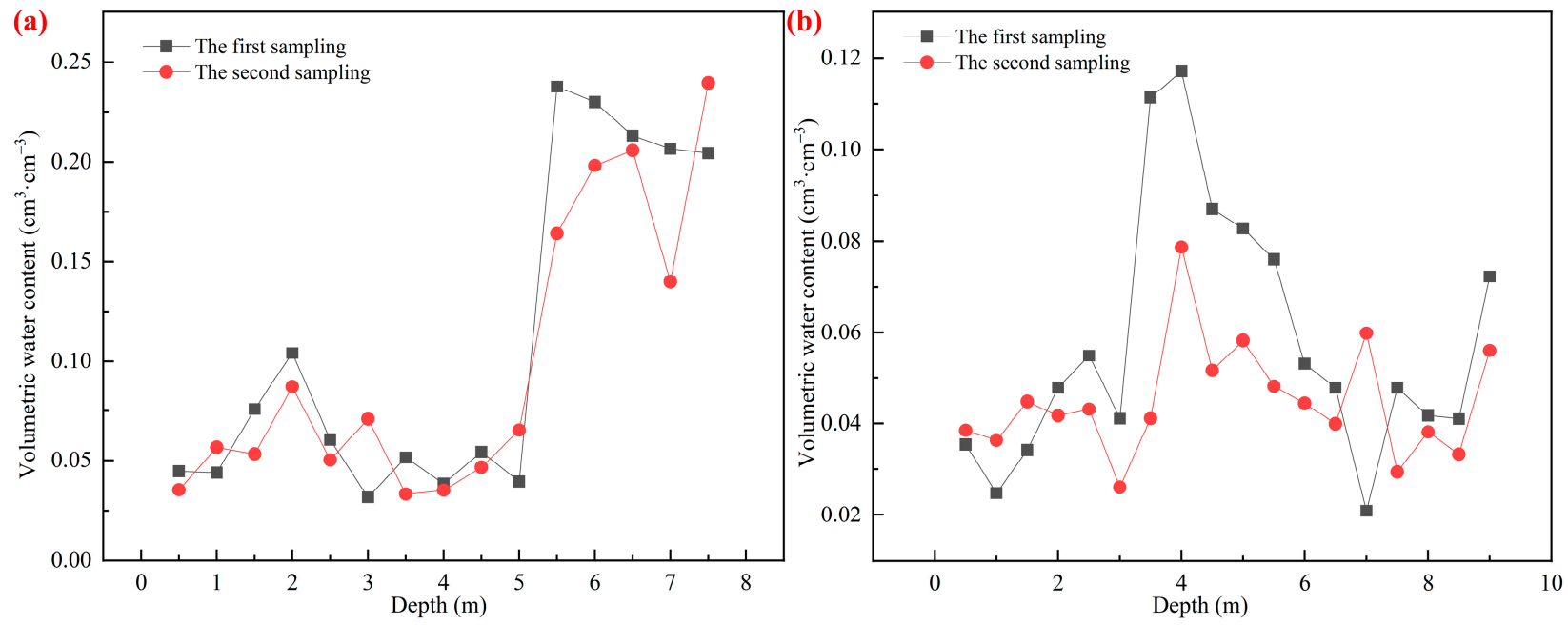

Figure 5. The change of SWC obtained by two samplings at No. 8 and No. 9 measuring points located in the area not affected by mining. (a) Change of SWC obtained from two samplings at No. 8 measuring point. (b) Change of SWC obtained from two samplings at No. 9 measuring point.

It can be seen in Figure 5 that compared with mining before, the overall average water content in SWC increases after mining at No. 8 and No. 9 is $-9.47 \%$ and $-6.79 \%$, respectively, the change is less than $9.50 \%$. The trends of SWC at different depths is basically the same. This shows that the changes of rainfall, temperature and other factors in the unmined area has little effect on the variation of SWC in the study area. It can reflect variation characteristics of shallow formation water content affected by mining through comparing the changes in the shallow formation water content of the study area before and after the mining of point samples No. 1-7.

We tested the SWC data in the study area before and after mining within the upper limit of $6 \mathrm{~m}$ in the depth direction of No. 1-7 measuring points to investigate the effect of SHM on the shallow SWC in the minefield. The distribution of SWC in the different level of depths before and after mining were averaged to analyze the changes in SWC affected by mining. The result is shown in Figure 6.

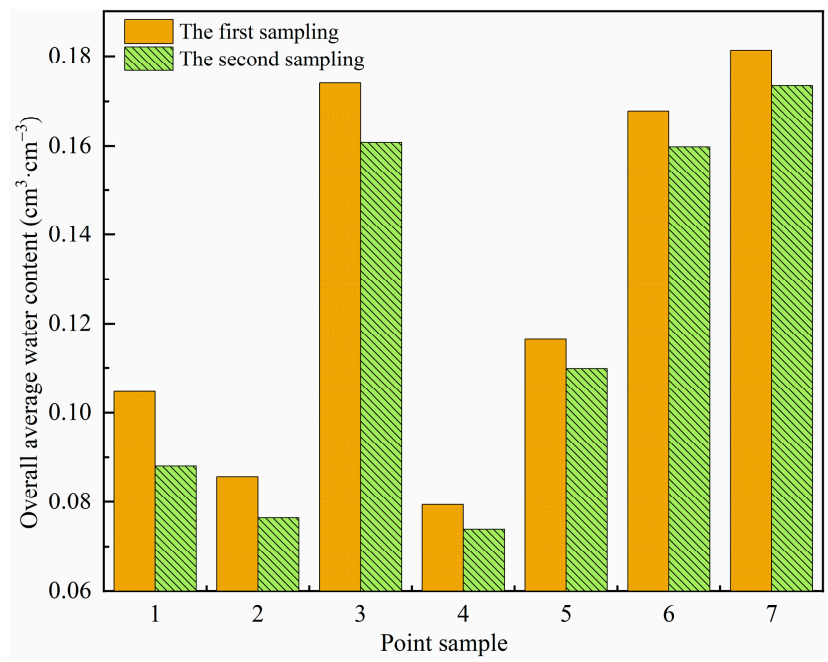

Figure 6. Overall average water content of the soil obtained by sampling at different times. The overall average water content is the average of all deep SWC at each sample.

One can see from Figure 6 that the shallow SWC shows a decreasing trend as a whole after the coal seam in the minefield is mined. The reason is that the overlying stratum 
sinks and breaks by layers after the shallow coal seam undergoes high-intensity mining. The mining damage is transmitted upwards to the surface, causing surface damage. The surface damage caused in the form of surface subsidence and cracks has destroyed the bedrock aquifer and even the loose aquifer near the surface. This changes the movement law of groundwater and soil moisture, which leads to the decline of groundwater level and the decrease of SWC.

We regressed the increase in the overall average water content at sampling points No. 1-7 to quantitatively analyze the amplitude of changes in the overall average water content before and after mining and the "self-recovery" characteristics of the surface SWC after mining. The regression curve is shown in Figure 7 . The negative value indicates that the soil overall average water content after mining is in a downward trend compared to that before mining. It can be seen from Figure 7 that the overall average water content of measuring points No. 1, 2, 3, 4, 5, 6, and 7 are 0.0881, 0.0765, 0.1608, 0.0739, 0.1099, 0.1598 , and $0.1734 \mathrm{~cm}^{3} \cdot \mathrm{cm}^{-3}$, respcetively. Compared with pre-mining, it has decreased by $15.84,10.84,7.63,6.93,5.63,4.82$, and $4.37 \%$, respectively, and the decreasing rate shows a gradual declining trend.

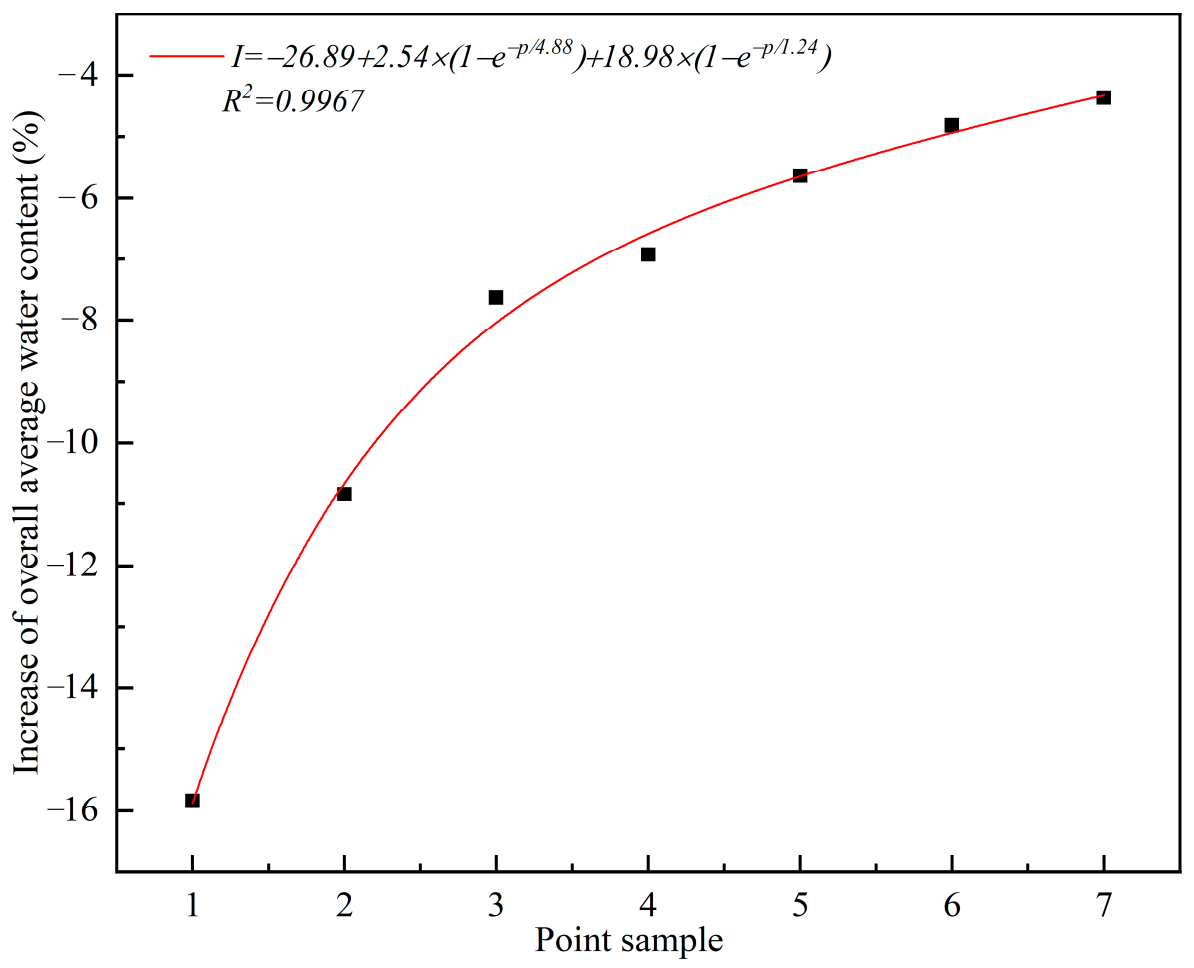

Figure 7. Regression curve of the increase rate of the overall average water content after mining.

The reason is that the goaf, as time goes by, has basically collapsed after the coal seam is mined, and gradually compacted during the main roof rotation and subsidence process. The surrounding rock tends to be stable, and the surface SWC shows "self-recovery" [53] feature. The measuring points from No. 1 to 7 are located in the trend direction of the working face, and the working face passes through measuring points 7 to 1 in sequence. The area where measuring point No. 1 is located, lags behind the working face for a short distance in the second sampling, so the SWC has a larger drop. The area where measuring point No. 7 is located lags behind the working face for a longer distance. At this time, the advancing position of the working face has left measuring point No. 7 area for more than 120 days. The surface has gone through a period of active subsidence and entered a stable period. The SWC has gradually recovered, so the drop in water content is relatively small. 
The increase of the overall average water content varies with the point samples along the trend direction of the working face, in accordance with the following formula:

$$
I=-26.89+2.54 \times\left(1-e^{\frac{-x}{4.88}}\right)+18.98 \times\left(1-e^{\frac{-x}{1.24}}\right), R^{2}=0.9967
$$

where $I$ is the increase in the overall average water content of the soil (\%) and $p$ is the point sample position along the trend direction of the working face.

\section{Conclusions}

This study first comprehensively evaluated the applicability and limitations of six typical soil dielectric models, and then compared the changes of shallow SWC in the wellfield before and after mining. The following conclusions can be drawn:

(1) Across the board, the fitting effect of the four empirical models (Topp et al. [43], Ledieu et al. [44], Malicki et al. [49], and Roth et al. [46]) and two semi-empirical models (Malicki et al. [49] and Roth et al. [48]) on the clay is better than that of the medium sand. The Ledieu model [44] has the best performance for medium sand and the Topp model [43] has the best performance for clay.

(2) The shallow SWC showed an overall decreasing trend, after the high-intensity mining of shallow buried coal seams, compared to the pre-mining period, the decrease showed a gradual downward trend. The shorter the lagging working face distance is, the greater the drop of SWC will be. The longer the lagging working face distance, the smaller the drop of SWC will be, showing a gradually stable trend.

(3) In this work, although we evaluated and studied the adaptability of several common dielectric models based on typical soils in the minefield, there is still a lack of dielectric models that are fully adapted to the special soil conditions in arid and semi-arid regions.

Author Contributions: Conceptualization, F.C. and Y.D.; methodology, Y.D.; software, Y.D.; validation, Y.D. and J.N.; formal analysis, S.P.; investigation, Y.D.; resources, F.C.; data curation, Z.Z.; writing — original draft preparation, J.N.; writing—review and editing, Z.Z.; visualization, Y.D.; supervision, Y.D.; project administration, F.C.; funding acquisition, F.C. All authors have read and agreed to the published version of the manuscript.

Funding: This research was funded by the Major Project of Shaanxi Coal and Chemical Industry Group Co. Ltd: Protection and Utilization of Water Resources \& Research and Demonstration of Key Technologies for Ecological Reconstruction in Northern Shaanxi Coal Mining Area (2018SMHKJ-A-J03) and the 2030 Pilot Project of CHN ENERGY Investment Group Co. Ltd: Research on Ecological Restoration and Protection of Coal Base in Arid Eco-fragile Region (GJNY2030XDXM-19-03.2).

Institutional Review Board Statement: Not applicable.

Informed Consent Statement: Not applicable.

Data Availability Statement: The data presented in this study are available on request from the corresponding author.

Conflicts of Interest: The authors declare no conflict of interest.

\section{References}

1. Xu, J.X.; Zhao, H.; Yin, P.C.; Bu, N.S.; Li, G. Impact of Underground Coal Mining on Regional Landscape Pattern Change Based on Life Cycle: A Case Study in Peixian, China. Pol. J. Environ. Stud. 2019, 28, 4455-4465. [CrossRef]

2. Cui, F.; Du, Y.F.; Chen, B.P.; Zhao, Y.X.; Zhou, Y.Q. Variation in shallow sandy loam porosity under the influence of shallow coal seam mining in north-west China. Energy Explor. Exploit. 2020, 38, 1349-1366. [CrossRef]

3. Bi, Y.; Xiao, L.; Guo, C.; Christie, P. Revegetation type drives rhizosphere arbuscular mycorrhizal fungi and soil organic carbon fractions in the mining subsidence area of northwest China. Catena 2020, 195, 104791. [CrossRef]

4. Bi, Y.; Wang, K.; Wang, J. Effect of different inoculation treatments on AM fungal communities and the sustainability of soil remediation in Daliuta coal mining subsidence area in northwest China. Appl. Soil Ecol. 2018, 132, 107-113. [CrossRef]

5. Guo, Y.; Liu, X.; Tsolmon, B.; Chen, J.; Wei, W.; Lei, S.; Yang, J.; Bao, Y. The influence of transplanted trees on soil microbial diversity in coal mine subsidence areas in the Loess Plateau of China. Glob. Ecol. Conserv. 2020, 21, e00877. [CrossRef] 
6. Hussain, R.; Luo, K. Geochemical valuation and intake of F, As, and Se in coal wastes contaminated areas and their potential impacts on local inhabitants, Shaanxi China. Environ. Geochem. Health 2018, 40, 2667-2683. [CrossRef]

7. Lv, X.; Xiao, W.; Zhao, Y.; Zhang, W.; Li, S.; Sun, H. Drivers of spatio-temporal ecological vulnerability in an arid, coal mining region in Western China. Ecol. Indic. 2019, 106, 105475. [CrossRef]

8. Shi, X.; Song, Z. The Silent Majority: Local residents' environmental behavior and its influencing factors in coal mine area. J. Clean. Prod. 2019, 240, 118275. [CrossRef]

9. Yang, Z.; Li, W.; Li, X.; Wang, Q.; He, J. Assessment of eco-geo-environment quality using multivariate data: A case study in a coal mining area of Western China. Ecol. Indic. 2019, 107, 105651. [CrossRef]

10. $\mathrm{Wu}, \mathrm{X}$; Lenon, G.P.; Dong, Y. The calculation of riverine ecological instream flows and runoff profit-loss analysis in a coal mining area of northern China. River Res. Appl. 2020, 36, 760-768. [CrossRef]

11. Xiao, W.; Fu, Y.H.; Wang, T.; Lv, X.J. Effects of land use transitions due to underground coal mining on ecosystem services in high groundwater table areas: A case study in the Yanzhou coalfield. Land Use Policy 2018, 71, 213-221. [CrossRef]

12. Li, P. Mine Water Problems and Solutions in China. Mine Water Environ. 2018, 37, 217-221. [CrossRef]

13. Liu, S.; Li, W.; Wang, Q. Height of the Water-Flowing Fractured Zone of the Jurassic Coal Seam in Northwestern China. Mine Water Environ. 2018, 37, 312-321. [CrossRef]

14. He, X.; Zhao, Y.; Zhang, C.; Han, P. A Model to Estimate the Height of the Water-conducting Fracture Zone for Longwall Panels in Western China. Mine Water Environ. 2020, 39, 823-838. [CrossRef]

15. Zhang, Y.; Cao, S.; Gao, R.; Guo, S.; Lan, L. Prediction of the Heights of the Water-Conducting Fracture Zone in the Overly-ing Strata of Shortwall Block Mining Beneath Aquifers in Western China. Sustainability 2018, 10, 1-20.

16. Xiao, W.; Zhang, W.; Ye, Y.; Lv, X.; Yang, W. Is underground coal mining causing land degradation and significantly dam-aging ecosystems in semi-arid areas? Study Ecol. Capit. Perspective. Land Degrad. Dev. 2020, 31, 1969-1989.

17. Wang, Q.; Li, W.; Li, T.; Li, X.; Liu, S. Goaf water storage and utilization in arid regions of northwest China: A case study of Shennan coal mine district. J. Clean. Prod. 2018, 202, 33-44. [CrossRef]

18. Xu, Z.; Li, Q.; Li, X.; Zhang, G.; Yang, Y.; He, W.; Wu, X. Structural evolution of overburden and surface damage caused by high-intensity mining with shallow depth. J. China Coal Soc. 2020, 45, 2728-2739.

19. Fan, L.; Ma, X. A review on investigation of water-preserved coal mining in western China. Int. J. Coal Sci. Technol. 2018, 5, 411-416. [CrossRef]

20. Yang, Z.; Li, W.; Li, X.; He, J. Quantitative analysis of the relationship between vegetation and groundwater buried depth: A case study of a coal mine district in Western China. Ecol. Indic. 2019, 102, 770-782. [CrossRef]

21. Wu, Z.; Xia, T.; Nie, J.; Cui, F. The shallow strata structure and soil water content in a coal mining subsidence area detected by GPR and borehole data. Environ. Earth Sci. 2020, 79, 500. [CrossRef]

22. Wu, Z.; Peng, S.; Cui, F.; Nie, J. Using ground penetrating radar combined with borehole to detect soil profile and water content in coal mining subsidence area. Trans. Chin. Soc. Agric. Eng. 2019, 35, $243-251$.

23. Wang, Y.; Bian, Z.; Lei, S.; Zhang, Y. Investigating spatial and temporal variations of soil moisture content in an arid mining area using an improved thermal inertia model. J. Arid Land 2017, 9, 712-726. [CrossRef]

24. Tai, X.; Hu, Z.; Chen, C. Monitoring soil moisture at different subsidence areas of mining in western windy and sandy re-gion with neutron instrument. Trans. Chin. Soc. Agric. Eng. 2016, 32, 225-231.

25. Kong, X.; Zhang, Q. Spatial distribution characteristics of arable land grade in Western China. Trans. Chin. Soc. Agric. Eng. 2012, $28,1-7$.

26. O'Kelly, B.C. Accurate determination of moisture content of organic soils using the oven drying method. Dry. Technol. 2004, 22, 1767-1776. [CrossRef]

27. Wang, C.; Zhao, C.; Qiao, X.; Hou, R. A Design of Probe for Measurement of Moisture Content Using Time Domain Reflec-tometry. Sens. Lett. 2010, 8, 118-121.

28. Xu, J.; Ma, X.; Logsdon, S.D.; Horton, R. Short, Multineedle Frequency Domain Reflectometry Sensor Suitable for Measuring Soil Water Content. Soil Sci. Soc. Am. J. 2012, 76, 1929-1937. [CrossRef]

29. Kodikara, J.; Rajeev, P.; Chan, D.; Gallage, C. Soil moisture monitoring at the field scale using neutron probe. Can. Geotech. J. 2014, 51, 332-345. [CrossRef]

30. Liu, X.; Dong, X.; Leskovar, D.I. Ground penetrating radar for underground sensing in agriculture: A review. Int. Agrophys. 2016, 30, 533-543. [CrossRef]

31. Capodici, F.; Maltese, A.; Ciraolo, G.; La Loggia, G.; D’Urso, G. Coupling two radar backscattering models to assess soil roughness and surface water content at farm scale. J. Sci. Hydrol. 2013, 58, 1677-1689. [CrossRef]

32. Danjon, F.; Reubens, B. Assessing and analyzing 3D architecture of woody root systems, a review of methods and applica-tions in tree and soil stability, resource acquisition and allocation. Plant Soil 2008, 303, 1-34. [CrossRef]

33. Lu, Y.; Song, W.; Lu, J.; Wang, X.; Tan, Y. An Examination of Soil Moisture Estimation Using Ground Penetrating Radar in Desert Steppe. Water 2017, 9, 521. [CrossRef]

34. Robinson, D.A.; Campbell, C.S.; Hopmans, J.W.; Hornbuckle, B.K.; Jones, S.B.; Knight, R.; Ogden, F.; Selker, J.; Wendroth, O. Soil moisture measurement for ecological and hydrological watershed-scale observatories: A review. Vadose Zone J. 2008, 7, 358-389. [CrossRef] 
35. Benedetto, A.; Benedetto, F. Remote Sensing of Soil Moisture Content by GPR Signal Processing in the Frequency Domain. IEEE Sens. J. 2011, 11, 2432-2441. [CrossRef]

36. Algeo, J.; Slater, L.; Binley, A.; Van Dam, R.L.; Watts, C. A Comparison of Ground-Penetrating Radar Early-Time Signal Ap-proaches for Mapping Changes in Shallow Soil Water Content. Vadose Zone J. 2018, 17, 180001. [CrossRef]

37. Binley, A.; Winship, P.; Middleton, R.; Pokar, M.; West, J. High-resolution characterization of vadose zone dynamics using cross-borehole radar. Water Resour. Res. 2001, 37, 2639-2652. [CrossRef]

38. Gerhards, H.; Wollschlaeger, U.; Yu, Q.; Schiwek, P.; Pan, X.; Roth, K. Continuous and simultaneous measurement of reflec-tor depth and average soil-water content with multichannel ground-penetrating radar. Geophysics 2008, 73, J15-J23. [CrossRef]

39. Qin, Y.; Chen, X.; Zhou, K.; Klenk, P.; Roth, K.; Sun, L. Ground-penetrating radar for monitoring the distribution of near-surface soil water content in the Gurbantunggut Desert. Environ. Earth Sci. 2013, 70, 2883-2893. [CrossRef]

40. Zhou, L.; Yu, D.; Wang, Z.; Wang, X. Soil Water Content Estimation Using High-Frequency Ground Penetrating Radar. Wa-ter 2019, 11, 1036. [CrossRef]

41. Turesson, A. Water content and porosity estimated from ground-penetrating radar and resistivity. J. Appl. Geophys. 2006, 58, 99-111. [CrossRef]

42. Cui, F.; Bao, J.; Cao, Z.; Li, L.; Zheng, Q. Soil hydraulic parameters estimation using ground penetrating radar data via en-semble smoother with multiple data assimilation. J. Hydrol. 2020, 583, 124552. [CrossRef]

43. Topp, G.C.; Davis, J.L.; Annan, A.P. Electromagnetic determination of soil water content: Measurements in coaxial trans-mission lines. Water Resour. Res. 1980, 16, 574-582. [CrossRef]

44. Ledieu, J.; De Ridder, P.; De Clerck, P.; Dautrebande, S. A method of measuring soil moisture by time-domain reflectome-try. J. Hydrol. 1986, 88, 319-328. [CrossRef]

45. Alharthi, A.; Lange, J. Soil water saturation: Dielectric determination. Water Resour. Res. 1987, 23, 591-595. [CrossRef]

46. Roth, C.; Malicki, M.; Plagge, R. Empirical evaluation of the relationship between soil dielectric constant and volumetric water content as the basis for calibrating soil moisture measurements by TDR. Eur. J. Soil Sci. 1992, 43, 1-13. [CrossRef]

47. Pepin, S.; Plamondon, A.P.; Stein, J. Peat water content measurement using time domain reflectometry. Can. J. For. Res. 1992, 22, 534-540. [CrossRef]

48. Roth, K.; Schulin, R.; Flühler, H.; Attinger, W. Calibration of time domain reflectometry for water content measurement using a composite dielectric approach. Water Resour. Res. 1990, 26, 2267-2273. [CrossRef]

49. Malicki, M.; Plagge, R.; Roth, C. Improving the calibration of dielectric TDR soil moisture determination taking into ac-count the solid soil. Eur. J. Soil Sci. 1996, 47, 357-366. [CrossRef]

50. Cosenza, P.; Camerlynck, C.; Tabbagh, A. Differential effective medium schemes for investigating the relationship between high-frequency relative dielectric permittivity and water content of soils. Water Resour. Res. 2003, 39, 1230. [CrossRef]

51. Chelidze, T.; Guéguen, Y. Electrical spectroscopy of porous rocks: A review-I. Theoretical Models Geophys. J. Int. 1999, 137, 1-15. [CrossRef]

52. Anbazhagan, P.; Bittelli, M.; Pallepati, R.R.; Mahajan, P. Comparison of soil water content estimation equations using ground penetrating radar. J. Hydrol. 2020, 588, 125039. [CrossRef]

53. Cui, X.; Peng, S.; Lines, L.R.; Zhu, G.; Hu, Z.; Cui, F. Understanding the Capability of an Ecosystem Nature-Restoration in Coal Mined Area. Sci. Rep. 2019, 9, 19690. [CrossRef] [PubMed] 